\title{
An Characteristics Analysis of the Fluidic Muscle Cylinder
}

\author{
DongSoo Kim*, SangKyu Bae*, Shin Huh** and SungIn Hong*** \\ * IT Machinery Research Center, Korea Institute of Machinery \& Materials \\ 171 Jang-Dong, Yuseong-Gu, Daejeon, Korea \\ (E-mail: kds671@kimm.re.kr) \\ ** Future Technology Department, Korea Institute of Machinery \& Materials \\ 171 Jang-Dong, Yuseong-Gu, Daejeon, Korea \\ *** Dept. of Mechanical Engineering, Chungnam National University \\ 220 Gung-Dong, Yuseong-Gu, Daejeon, Korea
}

\begin{abstract}
- The fluidic muscle cylinder consists of an air bellows tube, flanges and lock nuts. It's features are softness of material and motion, simplicity of structure, low production cost and high power efficiency. Recently, unlikely the pneumatic cylinder, the fluidic muscle cylinder without air leakage, stick slip, friction, and seal was developed as a new concept actuator. In this study, we carried out the finite element modeling and analysis about the main design variables such as contraction ration and force, diameter increment of fluidic muscle cylinder. On the basis of finite element analysis, the prototype of fluidic muscle cylinder was manufactured and tested. Finally, we compared the results between the test and the finite element analysis.
\end{abstract}

\section{KEY WORDS}

Fluidic Muscle, Nylon Fiber, Contraction Ratio, Finite Element Modeling, Cord Angle

\section{NOMENCLATURE}

E: Elasticity coefficient

B: Thickness of air bellows

$\mathrm{D}_{0}$ : Diameter of air bellows

L: Length of cylinder

$\mathrm{p}_{1}$ : Internal pressure of cylinder

$v:$ Poisson's ratio

$f:$ Contraction force

$\theta$ : Cord angle

\section{INTRODUCTION}

Because the pneumatic cylinder generally uses sliding seal, it causes the high friction force and adherence phenomenon when it operates in low speed. Therefore, it has a disadvantage of difficult precise control during the driving of the cylinder. Many researches on the shape of piston and micro-cylinder have been performed to overcome that disadvantage ${ }^{(1)(2)}$. But these cylinders have disadvantages such as difficulty in manufacturing and high price.

Recently, unlikely the pneumatic cylinder, the fluidic muscle cylinder without air leakage, stick slip, friction, and seal was developed as a new concept actuator. It has the characteristics such as light weight, low price, 
high response, durable design, long life, high power, high contraction, which is innovative product fulfilling RT(Robot Technology) which is one of the nation-leading next generation strategy technologies $6 \mathrm{~T}$ as well as cleanness technology

In this study, finite element modeling is performed to analyze the characteristics of fluidic muscle cylinder, and then the optimized design variables are determined by analyzing the contraction force, contraction ratio, and the change of diameter and pressure. The characteristics are confirmed by manufacturing the fluidic muscle cylinder and performing the experiments.

\section{THEORETICAL BACKGROUND}

Exact mathematical modeling is needed to understand the characteristics of fluidic muscle cylinder. Fig. 1 shows a schematic analysis model of fluidic muscle cylinder .

A portion of the Internal pressure applied to the fluidic muscle cylinder, $p$, is used to expansion of rubber itself, the remaining is transferred to the fiber cord. When the outer pressure of the tube applied to the fiber cord is expressed as $p_{1}$, equation (1) can be derived from the deformation correlation of axial stress and circumferential stress of the rubber tube.

$$
p_{1}=p-\frac{4 E B\left(D^{2}-D D_{0}\right)}{\left((2-v) D^{2}-v\left(D-D_{0}\right)^{2}\right) D_{0}}
$$

Where $\mathrm{E}, \mathrm{B}$ and $\mathrm{D}_{0}$ represent the elastic coefficient of air bellows, thickness and internal diameter, respectively, and $v$ represents Poisson's ratio.

When the internal pressure applies to the fluidic muscle cylinder, the bellows expand in radial direction. The direction of expansion force is changed by fiber cord and then it becomes the contraction force $\left(f_{1}\right)$,

$$
f_{1}=\frac{p_{1} D L}{2 \tan \theta}
$$

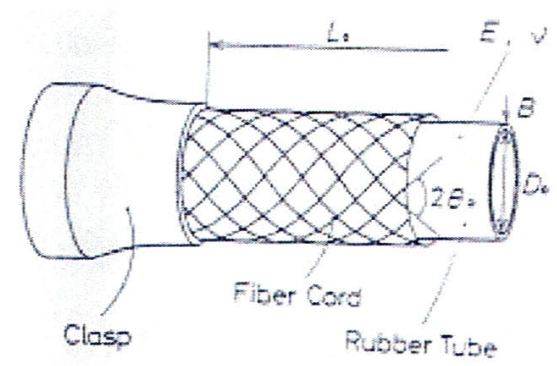

Figure1 Schematic diagram of fluidic muscle cylinder
Where, $L$ represents the length of air bellows, and $\theta$ represents the cord angle. Simultaneously, the internal pressure causes the extension force of axial direction $\left(f_{2}\right)$ to the end tip.

$$
f_{2}=\frac{\pi}{4}\left(D^{2}+\left(D-D_{0}\right)^{2}\right) p_{1}
$$

The balance of the force regarding actuator can be expressed as equation (4) by equation (3)

$$
f=f_{1}-f_{2}=\frac{p_{1} D L}{2 \tan \theta}-\frac{\pi}{4}\left(D^{2}+\left(D-D_{0}\right)^{2}\right) p_{1}
$$

Equation (4) shows that the contraction force $(f)$ is proportional to the internal pressure, $\mathrm{p}_{1}$, the diameter, (D), and the length (L), but it inversely proportional to the cord angle.

The preceding theoretical equation can give a tendency regarding the characteristics of fluidic muscle cylinder, but it cannot evaluate the quantitative characteristics of the real products.

\section{FINITE ELEMENT MODELING AND}

\section{ANALYSIS}

\subsection{The structure of fluidic muscle}

Fig. 2 shows the principal components of the fluidic muscle cylinder, which are composed of air bellows, flange, locking nuts. If the air pressure applies, the diameter of air bag increases and its length decreases. The cord papers aligned with nylon fiber are used to reinforce the rubber filled in high pressure for the tube, which is composed of 2 layers of cord papers.

The outer layer and inner layer are composed of rubber, in the medium each cord paper is aligned in the plus and minus angle on the basis of axis direction. Therefore, it plays a role to support most of load induced by air pressure.

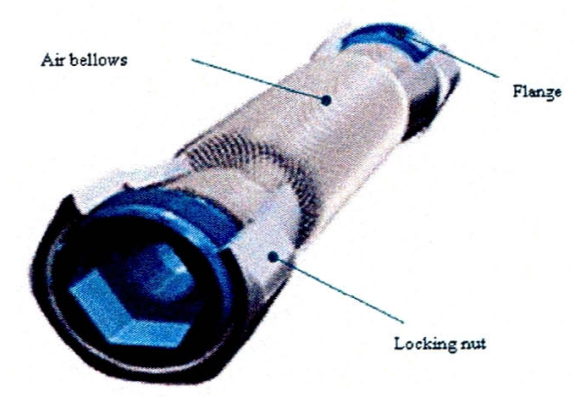

Figure2 Structure of fluidic muscle cylinder 
The rubber thickness of air bellows is $0.4 \mathrm{~mm}$, the rubber thickness of cord paper is $0.5 \mathrm{~mm}$, the rubber thickness between cord papers is $0.4 \mathrm{~mm}$, and the rubber thickness of outer region is $0.4 \mathrm{~mm}$. The diameter of nylon cord is $0.5 \mathrm{~mm}$, the gap between cords is $24 \mathrm{ea} / \mathrm{inch}$, and the cords are aligned in the angle of $\pm 30^{\circ}$ on the basis of axis direction.

\subsection{Modeling and deformation analysis}

The fluidic muscle cylinder is modeled by $3 \mathrm{D} 1 / 2$ symmetry model, and is analyzed with ABAQUS, the tool of finite element analysis. The air bellows is modeled by using S4R finite-strain shell elements, 3D F3D3 and F3D4 hydrostatic fluid cavity elements are used to calculate the change of pressure and volume inside of air bag.

The air inside air bellows is modeled by regarding it as ideal gas, the standard density of the air is $1.204 \mathrm{~kg} / \mathrm{m}^{3}$, the temperature of air is $23^{\circ} \mathrm{C}$, the atmospheric pressure is $101.36 \mathrm{kPa}$.

The cord paper is composed of nylon fiber, which is modeled with skew rebar. Contact modeling between air bag and right \& left locking nuts is expressed by defining contact pair between rigid element R3D4 and S4R shell elements. The boundary condition and restraint condition of the fluidic muscle restrain the degree of freedom in the center cutting point of both left and right locking nuts, and the center cutting point of right locking nut restrains corresponding degree of freedom according to analysis condition.

Fig. 3 shows finite element modeling of fluidic muscle cylinder. Mooney constant of rubber was used with the value of $\mathrm{C}_{10}=0.207 \mathrm{~N} / \mathrm{mm}^{2}$ and $\mathrm{C}_{01}=0.234 \mathrm{~N} / \mathrm{mm}^{2}$, elastic coefficient of nylon cord modeled with rebar is $\mathrm{E}=73,000 \mathrm{~N} / \mathrm{mm}^{2}$, and Poisson's ratio is $\mathrm{v}=0.3$. $^{(3)}$

\subsection{Analysis of performance change by cord angle change}

Because the static characteristics of fluidic muscle cylinder generally depends on cord fixing angle, the effect of the change of cord fixing angle on the static characteristics of fluidic muscle cylinder was analytically predicted.

Fig. 4 shows the change of contraction ratio and diameter by cord angle change in the fluidic muscle cylinder with diameter of $\phi 10, \phi 20, \phi 40 \mathrm{~mm}$, and it is shown that as the cord angle decreases, contraction ratio and tube diameter increase.

Fig. 5 shows the contraction ratio and contraction force by the variation of cord angle. As the cord angle decreases, acted force and contraction ratio increase. The optimized value should be determined, considering that as the cord angle becomes smaller, the contraction force due to air pressure and slope increase, on the contrary tube diameter increases.

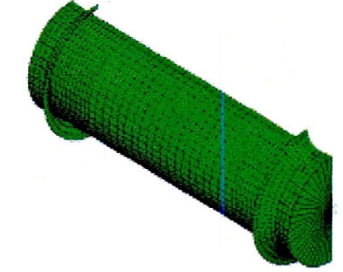

Figure3 FEA model of Fluidic muscle cylinder

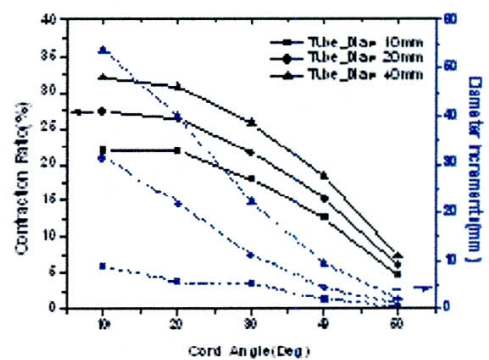

Figure4 Contraction ratio and diameter about the variation of cord angle

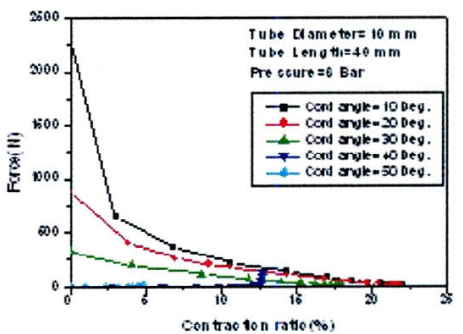

(a) $\phi 10 \mathrm{~mm}$

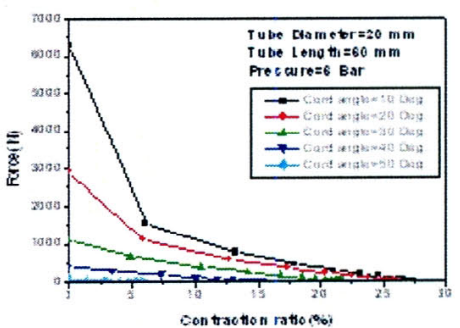

(b) $\phi 20 \mathrm{~mm}$

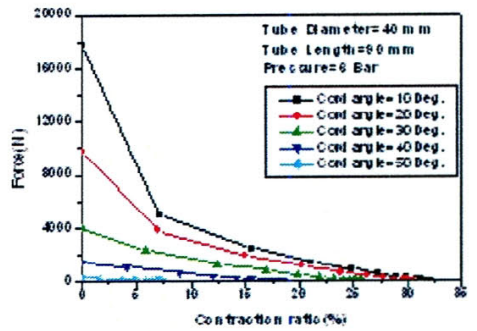

(c) $\phi 40 \mathrm{~mm}$

Figure 5 Contraction ratio and force about the variation of cord angle 
When the cord angle is $30^{\circ}$, proper maximum contraction ratio is maintained, so corresponding load is continuously acted. Accordingly, the cord angle of $30^{\circ}$ shows the optimized performance.

\subsection{Finite element analysis of manufacturing product}

The characteristics according to the variation of cord angle which is main variable of fluidic muscle cylinder with the diameter of $\phi 10, \phi 20, \phi 40 \mathrm{~mm}$ was analyzed, and then the optimized dimension and cord angle were determined and the analysis was performed. Fig. 6 shows FEA results of diameter increment ratio due to the variation of air pressure. From the figure it is confirmed that up to air pressure of 3 bar the slope of diameter increment ratio is steep, beyond that the slope becomes dull.

Fig. 7 shows FEA results of contraction ratio and contraction force due to the variation of air pressure from 1 to 6 bars. According the results, the contraction ratio and contraction force have an increasing tendency as the air pressure increases.

When tube diameter is $\phi 10 \mathrm{~mm}$, the maximum contraction force was $327.7 \mathrm{~N}$, and maximum contraction ratio was $18.0 \%$ in case of 6 bar air pressure.

When tube diameter is $\phi 20 \mathrm{~mm}$, the maximum contraction force was $1113.7 \mathrm{~N}$, and maximum contraction ratio was $21.7 \%$ in case of 6 bar air pressure.

When tube diameter is $\phi 40 \mathrm{~mm}$, the maximum contraction force was $3930.0 \mathrm{~N}$, and maximum contraction ratio was $25.7 \%$ in case of 6 bar air pressure.

From the analysis, the results on the deformation shape and the ratio of tube were obtained for the fluidic muscle cylinder with a diameter of $\phi 10, \phi 20, \phi 40$ $\mathrm{mm}$ by finite element model for air pressure of 6 bar as shown in Fig. 8. And then the fluidic muscle cylinder was manufactured by reflecting the optimized conditions in the design. The Mises maximum stress of rubber occurs in the central region of tube, which are $1.05 \mathrm{~N} / \mathrm{mm}^{2}, 1.19 \mathrm{~N} / \mathrm{mm}^{2}$, and $1.25 \mathrm{~N} / \mathrm{mm}^{2}$

\section{MANUFACTURING OF THE PRODUCT AND EXPERIMENT}

\subsection{Design and manufacturing of the product}

The fluidic muscle cylinder with optimized conditions was designed and manufactured on the basis of analysis results. Fig. 9 is the prototypes of assembled fluidic muscle cylinder with a diameter of $\phi 10, \phi 20$, $\phi 40 \mathrm{~mm}$.

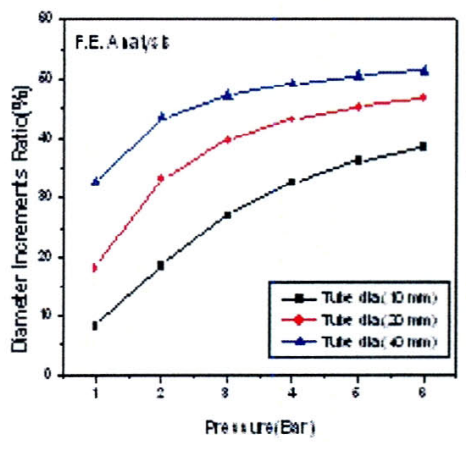

Figure6 FEA results of diameter increment ratio about the variation of air pressure

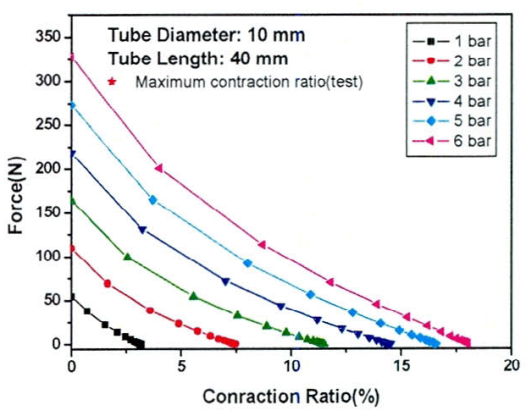

(a) $\phi 10 \mathrm{~mm}$

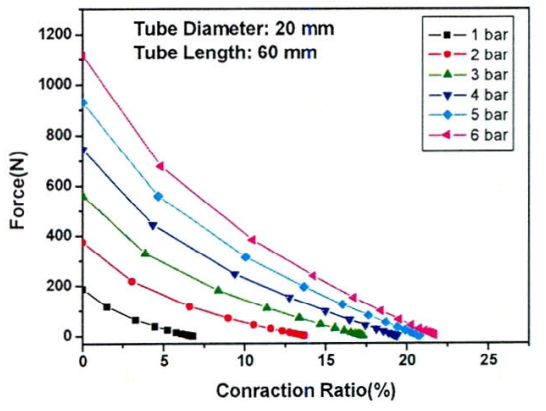

(b) $\phi 20 \mathrm{~mm}$

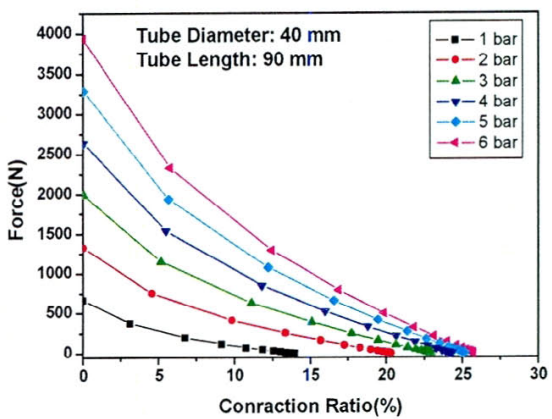

(c) $\phi 40 \mathrm{~mm}$

Figure7 FEA results of contraction ratio and force about the variation of air pressure 


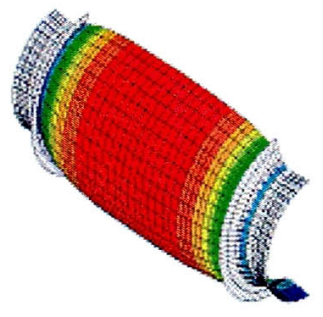

(a) $\phi 10 \mathrm{~mm}$

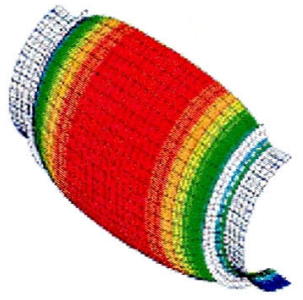

(b) $\phi 20 \mathrm{~mm}$

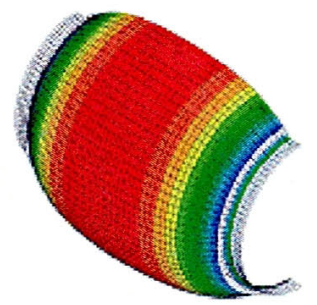

(c) $\phi 40 \mathrm{~mm}$

Figure8 Deformation shape of air bellows for air pressure of 6 bars (Cord angle $=30 \mathrm{deg}$.)

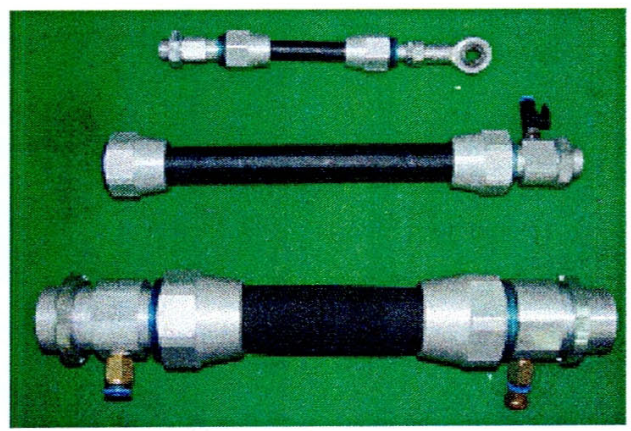

Figure9 Prototypes of fluidic muscle cylinder

\subsection{Composition of experimental apparatus and experiment}

The experimental apparatus for the performance evaluation was composed as Fig. 10. The compressed air is controlled by servo valve, load cell was attached to measure the force, position and velocity sensor, LVDT, was also attached, the sensors to measure pressure and flow rate was attached. ${ }^{(4)}$

Fig. 11 (a) and (b) show before and after pictures of pressure provision of manufacturing product. The contraction variation in the axial direction and expansion variation in the radial direction were measure and the contraction ratio was calculated by pressurizing the one side of cylinder and closing the other side.
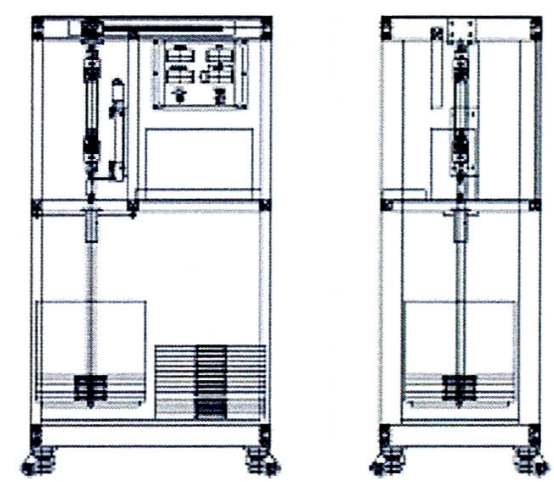

Figure10 Performance test apparatus

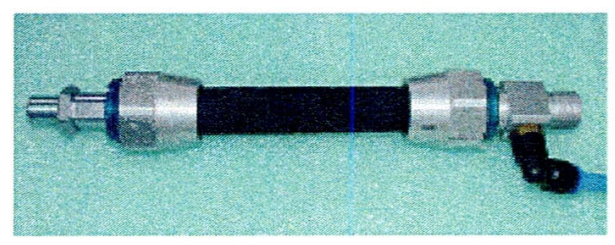

(a) Air pressure, $p=0$ bar

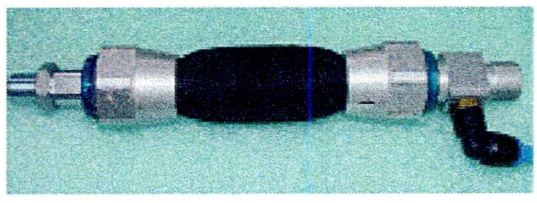

(b) Air pressure, $p=6$ bar

Figure11 Tests of fluidic muscle cylinder

4.3 Experimental results on contraction ratio and diameter incremental ration

Fig. 12(a) and (b) shows contraction ratio of the cylinder in the axial direction and diameter increment ratio due to pressure variation. The contraction ratio increases as the diameter of bellows increases, especially when air pressure is more than 4 bars, the contraction ratio abruptly decreases. The diameter increment ratio increases as the diameter of air bellows increases, especially when air pressure is more than 3 bars, the increment ratio abruptly decreases.

Comparing the experimental results of contraction ratio with analysis results, the error was evaluated to be $0.2 \%$ in case of $\phi 10 \mathrm{~mm}, 3.5 \%$ in case of $\phi 20 \mathrm{~mm}$ and $2.2 \%$ in case of $\phi 40 \mathrm{~mm}$ at the pressure of 6 bars. For the radial expansion ratio, the error was $4.7 \%$ in case of $\phi 10 \mathrm{~mm}, 4.3 \%$ in case of $\phi 20 \mathrm{~mm}$ and $12.7 \%$ in case of $\phi 40 \mathrm{~mm}$.

Therefore, it is believed that the results of finite element analysis are reliable. 


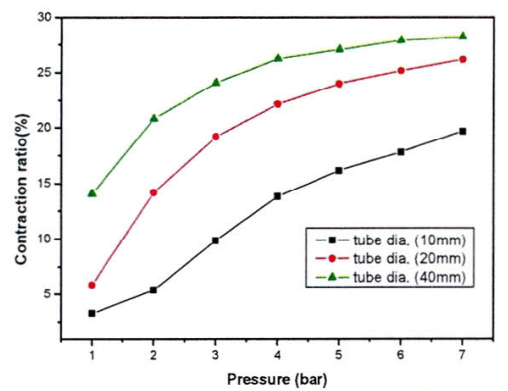

(a) Contraction ratio $(\%)$

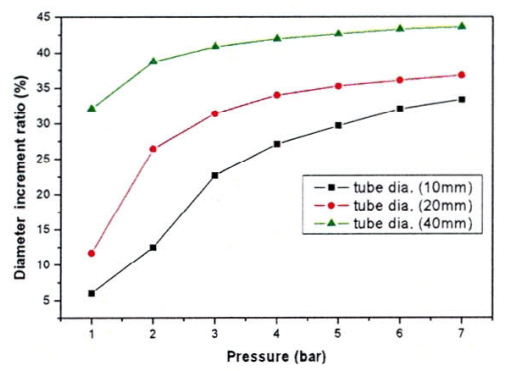

(b) Diameter increment ratio (\%)

Fig. 12 Test results of contraction and diameter increment ratio

\section{CONCLUSIONS}

In this study, principal design variables were determined by performing the finite element analysis for the characteristics of fluidic muscle cylinder. As the results of manufacturing of the test product and the characteristics experiments, following conclusions were drawn.

1. Principal design variables were determined through the finite element analysis by predicting the contraction ratio, contraction force and diameter variation ratio as a function of cord angle.

2. On the basis of analysis results, the fluidic muscle cylinder with the diameter of $\phi 10, \phi 20, \phi 40 \mathrm{~mm}$ was manufactured and then the experiments for contraction ratio and diameter variation ratio as a function of air pressure were performed.

3. On the basis of comparative results for the experimental values of the test product with the diameter of $\phi 10, \phi 20, \phi 40 \mathrm{~mm}$ and analytical values, the errors of the contraction ratio and diameter variation ratio were less than $5 \%$ and $12.7 \%$, respectively. But, it is believed that the results between experimental values and analytical values agreed well, considering non-linearity of rubber and anisotropic alignment of the cords.
4. It is confirmed that the deformation and characteristics of fluidic muscle cylinder can be predicted relatively well. On the basis of that it is believed that it can highly contribute to develop the new products.

\section{ACKNOWLEDGEMENTS}

This paper is a part of research project, "Development of Fluidic Muscle Cylinder," which is technology development project for components and materials by Ministry of Commerce, Industry and Energy. The author gratefully acknowledges the financial support of the Ministry of Commerce, Industry and Energy.

\section{REFERENCES}

1. G. Belforte, T. Raparelli, M. Velardocchia, "Study of the behavior of lip seals in pneumatic actuators", Lubrication Engineering, Vol. 49, No. 10, pp. 775-780, 1993.

2. G. Belforte, T. Raparelli, A. Trivella, "Study and development of innovative pneumatic microcylinders", Conference of Hydraulics and Pneumatics, Germany, pp. 235-248, 1995.

3. 橫田, 小松建浩, “A Study on a Flexible Hydraulic Actuator for Space Manipulators,” 日本機械學會 論文集(C編)，57 卷 542 号 3222-3227, 1991.

4. C.W. Ju, "A Study on the Development for Fluidic Muscle Cylinder," 1st Final Report, 2004. 